\title{
Evaluation criteria and film narrative. A frame to teaching relevance in audio description
}

\begin{abstract}
The filmic product undergoes a process of deconstruction and selection by the describer, who must decide which particular elements of the characters, costumes, set and action are to remain. Given its importance for professional practice, the acquisition of an appropriate yet flexible concept of relevance for audio descriptions is one of the main aims of any AD course, but how can translator trainees learn to decide what to describe? This paper presents a teaching proposal aimed at tackling the problem of relevance in audio description through the combined use of evaluation criteria and film narrative.
\end{abstract}

\section{Introduction}

Audio description (AD) in Spain is at present in a favourable position. On the one hand, there has been a subtle yet noteworthy rise in its practice. The percentage of ADs in television programming and DVDs is far from being close to the numbers in other European countries such as Great Britain or Germany. Yet, the mere fact of having overcome the previous situation, where ADs were almost exclusively done by private associations for the blind (cf. Orero, 2007), and having reached the general public market, is of significant relevance. On the other hand, the shifts in focus which always seem to guide research have lead the academic world of Audiovisual Translation (AVT) in the last two years to become increasingly aware of AD: It has become the focus of several research groups, conferences, workshops and books (Braun, 2008). However, and for the time being, this interest has not yet produced a wide variety of descriptive research to account for the actual characteristics of the descriptions made in Spain or elsewhere. Finally, as a consequence of the increase in AD practice and research, Spanish universities have also included AD courses both in undergraduate and postgraduate programmes (Badia \& Matamala, 2007).

In this context, $\mathrm{AD}$ teachers have to juggle between reference texts, samples of everyday practice and existing guidelines in an attempt to set the standards which will guide students in their future practice. As Remael and Vercauteren say (2007, p. 74): decisions and teach them how to evaluate different translation choices. 
Some of the hardest decisions for AD students to make regard relevance, the selection and prioritisation of the information that best conveys in the linguistic code of the description the multi-coded message portrayed by the original. The Universitat Jaume I in Castelló was a pioneer in introducing AVT at an undergraduate level from the very creation in 1993 of the degree in Translation and Interpreting. As a response to the social demand for media accessibility, it seemed only natural to include a specific course in Subtitling for the Deaf and Hard of Hearing (SDH) and AD within the AVT specialisation, starting in May 2007. The theoretical approach to teaching relevance in AD presented in this paper was designed for this one-term course.

\section{The problem of prioritisation}

Unlike dubbing and subtitling, the practice of AD in Spain has been regulated from early on by an official set of guidelines -Norma UNE 153020 (AENOR, 2005). It is advisable to familiarise students with the conventions it contains in order to prepare them for future practice, so these guidelines must be taken as a starting point for a systematic approach to the prioritisation of information in Spanish AD courses. However, it should not be regarded as the sole reference document. After a thorough comparison between the Spanish and British guidelines, Bourne and Jiménez (2007) concluded that the conventions displayed in the Norma UNE appear to represent just one particular concept of $\mathrm{AD}$ which is, furthermore, not confirmed to be based on the actual preferences of receivers (ibid.: 186). In a more generic approach, Chao states that there are two possible positions that may be adopted by describers (as cited by Yeung, 2007, p. 241):

They can take the subsidiary role of co-narrators translating certain signs for theunsighted audience. Co-narrators perform a task similar to 'filling blanks'. But describers can also take the pro-active role of independent narrators, taking control of the overall product by making their own narration, the dialogues and soundtrack work together. 
It becomes apparent that there is not yet a clear univocal standard for audio descriptions and that students, the future describers, should be capable of producing different kinds of descriptions in order to adapt to any given context. An AD course must consequently provide them with the tools to do so by taking into account as many existing guidelines as possible and, ideally, previous practices. Vercauteren (2007) compiled information from the Spanish, British, German and Flemish guidelines to provide the outline of a set of future European guidelines, and concluded that they present approximately the same structure of information to be described, organised in three areas: What to describe, When to describe it and How to describe it. But there is something else all guidelines have in common, their emphasis on prioritising all this information. Indeed, Matamala and Orero (2007) consider the ability to select critical information to be one of the basic competences which should be achieved by learning describers.

But how can this be done? Which elements make the describer choose among the list of what, when and how? There has been little research on the subject (Braun, 2008), and the few answers provided so far remain vague (cf. Remael \& Vercauteren, 2007, p. 76; Vercauteren, 2007, p. 148;). Salway (2007, p. 152) states that "AD will concentrate on providing sufficient information, complementary to the dialogue, so that audiences are able to understand who is doing what, where and why". However, he does not specify what "sufficient" implies, or by which means we can be sure that audiences do understand the product with our descriptions. Regarding the AD process, Poethe (2005, p. 40) considers that describers imagine a prototype AD whose features are to be incorporated in the real description. But he does not provide an account of how these main features are to reach the describer's subconscious to build up the given prototype. The English Guidelines affirm that "the describer must learn to weed out what is not essential" (Audetel, 2000, p. 13), but once again there is no account of how this is to be 
done. These guidelines do contain a small chapter dedicated to relevance, but it provides scant guidance that could be used for didactic purposes. Three recommendations are made, namely:

- Setting the scene

- Providing clear descriptions as the main aim of audio description, especially clarifying who is speaking at any given moment.

- Keeping descriptions to the point, since describing too much can be exhausting, irritating or dilute the mood of a scene

Implicitly, then, both researchers and authors of guidelines rely on the professional describer's background to choose which elements to describe in each specific situation — and by background we mean not only the awareness of the audiovisual text components, the cinematic devices, the intertextualities and narrative clues, etc. but also the knowledge acquired from practice. This assumption is perfectly reasonable in a professional context, but some problems arise when it is taken into the classroom (cf. Braun, 2008, p. 15).

Firstly, we cannot simply presume our students will have the necessary background for a reasoned decision-making with regards to relevance. This will depend on the characteristics of each course and its potential students (undergraduate or postgraduate, as part of a general translation degree, or part of a specific Master's degree in AVT, or even part of a specialisation course aimed at professional translators, etc.) and therefore must be dealt with and solved individually. The students for which our theoretical approach was constructed present a clearly defined profile: being in the last course of a translation degree and having already attended courses on dubbing and subtitling, they are well aware of the multi-coded nature of the audiovisual text and its implications for translation. However, in an academic context, the specificities of audio description demand that basic rules be exposed regarding relevance. This leads us to the second and most important problem: the necessary aim at objectiveness in the teaching and 
evaluation of relevance in audio descriptions. Put another way, are we as teachers entitled to evaluate the students' choices without having told them how to choose? Evaluation must be objective and based on measurable elements, and that is why we need, as Vercauteren says (2007, p. 140), a "set of structured, clear guidelines" to be applied, in this case, to the selection of items from the above mentioned list of what, when and how. However, such guidelines must not only be structured and clear, but also open enough to be applied to all possible situations in a given film or play. We must therefore face the challenge of conciliating the specificity of relevance with the need for structured and reasoned decision-making by students.

Remael and Vercauteren (2007) have designed and applied a model based on the analysis of the exposition phase of films through the twelve narrative strategies discussed by Lucey (1996) ${ }^{1}$. This model helps students identify relevant visual clues which are later included in their descriptions. As we will see, film narrative is indeed a valuable tool to tackle the issue of relevance, which structures the students' mental processes. However, some degree of subjectivity still remains in an approach which considers solely filmic narrative. Our proposal intends to reach a higher level of objectivity through the integration of evaluation in the process of decision-making. By self-evaluating their descriptions from the very first moment, the students learn to systematize their choices; thus, evaluation becomes not only a final assessment, but also a means of reflection.

As a result, we present a multi-faceted approach, synthesized in fig. 1, in which final decisions regarding relevance depend on the combination of three factors. On the one hand, the knowledge of the list of items which should ideally be described -Poethe's prototypical $\mathrm{AD}-$, which is brought to us by the existing literature on $\mathrm{AD}$ (represented

1 Lucey's strategies are visuals from action, grand images, visual metaphors, symbols, continuity visuals, mood and set-up visuals, wallpapering, walk-and-talk-scenes, business, image systems and settings, as cited by Remael and Vercauteren (2007). 
as "guidelines" in the figure). On the other hand, the evaluation criteria, which guide the process of selecting items from this list, especially in less context-ridden occasions, hence the two-way arrow. And finally, a narrative analysis of the film will contribute to more systematic decisions at any point of the process. In the following sections each of the three factors will be discussed separately in greater detail.

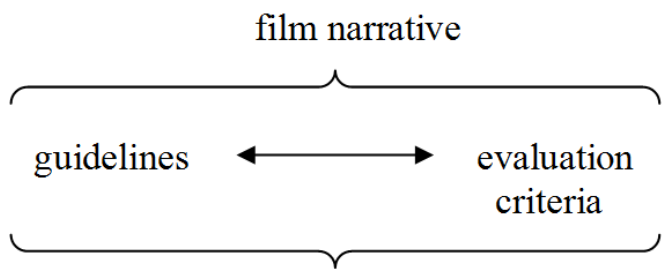

film narrative

Fig. 1: Theoretical approach for the teaching of relevance

\section{Guidelines: types of information to be described}

For this first factor, a combination of existing guidelines and research was deemed most appropriate, aiming to grant the students with the widest possible range of options, so that they might eventually adapt their descriptions to very different AD styles. The following is a very schematic list of the main questions concerning a description: what should be described (i.e. the items which should ideally be described), when the description should be inserted and how the description should be written. This specific factor has been the object of other research, and it is not our aim to provide a different perspective, but rather to combine the information presented in the British and Spanish guidelines and in the studies conducted by Vercauteren (2007), Salway (2007) and Turner (1998). ${ }^{2}$

(1) What to describe

a. Images

i. Where: setting, spatial relations between characters, movement of characters

ii. When: film time

2 For further insight on this topic we refer to these authors as well as to Audetel (2000) and AENOR (2005). 
iii. What: action

iv. Who: physical description, facial and corporal expressions, clothing, occupation and roles

v. How: lighting, décor, attitudes

b. Sounds: difficultly identifiable sounds, song lyrics, languages other than the source language

c. On-screen text: logos, opening titles and credits, cast lists, text on signs, subtitles

(2) When to describe

a. During silences, although background noise, music soundtrack or distant conversations may be overlapped by descriptions when necessary

b. Suspense and tension should not be tampered with by description

c. The original must be able to breathe through the description, too much description can be tiring

d. The description must be synchronised with action.

i. Scenes can be announced beforehand only on specific occasions and never if this gives away the plot

ii. Exception: sound effects can be described beforehand, or their description can be delayed if it is more effective in terms of narrative tension

(3) How to describe

a. Clarity in exposition is essential

i. Script must be fluent, straightforward, adequate, varied, euphonic and without redundancies

ii. Precise and specific vocabulary should be used

b. Vocabulary and style must accompany the original's

c. Present tense should be used

d. $1^{\text {st }}$ person pronouns should be avoided, except in children's programmes

e. Clearly biased or personal interpretations should be avoided

This list was created for inclusion in a course manual that intends to provide the

students with a very broad and open concept of audio description for recorded

programmes from a European perspective. Positive as this is, the drawbacks of such a

broad list are immediately apparent: it is impossible to include all the items in a

description, hence the importance of guiding the students through the selection process.

Our first strategy to help the students decide comes from evaluation criteria.

\section{Evaluation criteria}

The quality assurance promoted by the Declaration on the European Space for Higher

Education has triggered a commitment to adopt student-centred methodological approaches, such as portfolios, problem-based learning, peer-evaluation, etc. All such 
methods pay special attention to evaluation as an integral part of the teaching-learning process. According to Klenowski (2004), the use of explicit criteria helps to establish goals and expectations. If properly applied, a clear set of evaluation criteria may work not only as an assessment guide for the teacher or students, but also as a means to formative evaluation. In order to do so, it is crucial that students be informed of what is expected from them from the very start, and that evaluation criteria be known, shared, and compiled in a public document (IDES, 2008).

In fact, with the evaluation criteria we present, our aim was to create a guide which would help students not only to assess their final descriptions, but also to reflect during the process of describing. We must remember that the first step -and perhaps the most difficult- when learning to describe is to deal with the feeling of leaving things out. There is too much information on screen and students may feel at a loss when trying to prioritise information. A correction guide works as a reminder of the previously mentioned list of items to describe by highlighting the first bits of information that might be discarded, when facing time constraints, and those which must remain. By confronting their descriptions with this guide, the students are able to weed out, in Audetel's words, what is not essential.

The Department of Translation at the Jaume I University based its official evaluation criteria for translation corrections on Hurtado (1999). As academic literature on AD did not provide any proposal of didactic-oriented evaluation criteria, this document was taken as a base for the design of the correction guide presented in this paper. Thus, following AENOR (2005), Audetel (2000), Díaz-Cintas (2007), Matamala and Orero (2007), Bourne and Jiménez (2007), and Vercauteren (2007), the original items were amended and extended in order to apply to the specificities of AD. The following table 
is the list of possible mistakes to be avoided, with the acronyms used in exercise correction.

For the purpose of clarity, the table is divided in two, Table 1a contains general correction criteria elaborated by the Department of Translation which, however general, can also be applied to AD; Table 1b, which we will be looking at in more detail, shows $\mathrm{AD}$-specific evaluation criteria and those requiring an $\mathrm{AD}$-specific sub-section.

Table 1a. Evaluation criteria for audio descriptions in an academic context: General items

\begin{tabular}{|l|l|}
\hline NMS & $\begin{array}{l}\text { Not making sense } \\
\text { Difficult to understand, unclear phrasing, not making sense at all. }\end{array}$ \\
\hline GR & $\begin{array}{l}\text { Grammar } \\
\text { Syntax and morphology errors. }\end{array}$ \\
\hline DIAL & $\begin{array}{l}\text { Dialect } \\
\text { Deviates from the original's geographical, temporal or social dialect; } \\
\text { inappropriate deviations from standard, failure to convey idiolect. }\end{array}$ \\
\hline REG & $\begin{array}{l}\text { Register } \\
\text { Inconsistencies in field, mode or tenor with respect to the original. }\end{array}$ \\
\hline TEX & $\begin{array}{l}\text { Textual } \\
\text { Lack of coherence, lack of logic, poor use of conjunctions. } \\
\text { intertextual references. } \\
\text { Semiotics } \\
\text { Macrosigns: unsolved extralinguistic references or cultural implications. }\end{array}$ \\
\hline
\end{tabular}


Table 1b. Evaluation criteria for audio descriptions in an academic context: Specific items

\begin{tabular}{|c|c|}
\hline \multicolumn{2}{|c|}{ Linguistic transfer } \\
\hline VOC & $\begin{array}{l}\text { Vocabulary } \\
\text { Barbarisms, inappropriate lexical choices. } \\
\text { AD: Vagueness, use of non-specific vocabulary; inadequacy to the vocabulary } \\
\text { of the text to be described }{ }^{3} \text {. }\end{array}$ \\
\hline ST & $\begin{array}{l}\text { Style } \\
\text { Cacophonies, pleonasms, unnecessary repetitions, poor style. Deviates from } \\
\text { the style of the text to be described. } \\
\text { AD: Not complying with stylistic norms of AD. }\end{array}$ \\
\hline \multicolumn{2}{|c|}{ Pragmatic and Intersemiotic transfer } \\
\hline PRA & $\begin{array}{l}\text { Pragmatics } \\
\text { Inability to convey the intentionality, irony, inferences, presuppositions, } \\
\text { implications, illocutionary acts of the text to be described. } \\
\text { AD: Addition of non-intended pragmatic information. }\end{array}$ \\
\hline SUP & $\begin{array}{l}\text { Suppression } \\
\text { Suppression of visual, acoustic or textual information needed to understand } \\
\text { the text, especially setting the scene (plot, time and space) and the characters } \\
\text { in the scene. Suppression of relevant thematic connections. }\end{array}$ \\
\hline EX & $\begin{array}{l}\text { Excess } \\
\text { Obscuring dialogue with } \mathrm{AD} \text {, diluting the mood of the scene with too much } \\
\text { description, covering too much musical information. }\end{array}$ \\
\hline
\end{tabular}

3 By "text to be described" or, in short, "text" we refer here and throughout the table to the version which will reach the audience, comprising dialogues, images and sound. The usual practice in Spain for recorded products presents $\mathrm{AD}$ with the dubbed version of dialogues, when the product is not originally in the same language of the description (Matamala \& Orero, 2007, p. 333). In such cases, the assessment should be made taking into account the dubbed version, and not the original. 


\begin{tabular}{|l|l|}
\hline \multicolumn{1}{|l|}{} & $\begin{array}{l}\text { Describing obvious elements, redundant with the information conveyed by the } \\
\text { acoustic channel. }\end{array}$ \\
\hline Time management \\
TM & $\begin{array}{l}\text { Timing } \\
\text { Bescription is not synchronized with action. } \\
\text { description. }\end{array}$ \\
\hline PC & $\begin{array}{l}\text { Pace } \\
\text { Too long a description for the given fragment, has to be read too quickly. } \\
\text { Too concentrated a description for a long fragment. }\end{array}$ \\
\hline
\end{tabular}

The evaluation items revolve around three main axes, which roughly cover the what (including how much), when, and how sections of the guidelines. We have labelled them "Linguistic Transfer", "Pragmatic and Intersemiotic Transfer" and "Time Management". The first one is purely linguistic, related to the formal specificities required by the description (thus, the how section), and it includes "vocabulary" and "style". The what and how much section is here reflected in the items "pragmatics", "suppression" and "excess", all related to the ability of transforming extra-linguistic information (be it visual, acoustic, pragmatic or textual), into the linguistic form. The category "excess" acts as a bridge between sections, as it also covers items about when to describe (i.e. covering dialogue/music with $\mathrm{AD}$ ). Finally, the last group of evaluation items is formed by "timing" and "pace", both of them related to the adequate management of time, a crucial factor in any type of audiovisual translation and representing the when section of the list. 
Our main aim with these criteria is, as we said, not only to use them as a shared reference for the evaluation of descriptions, but also as a direction-sheet in the process of choosing relevant information. The items within the category "Pragmatic and intersemiotic transfer" are central in this matter, for this is where the recommendations on relevance stated by Audetel (2000) are concentrated. Still, the rest of these items affect the final description in various ways, and therefore are equally important in the decision-making process. An adequate "pace" does not allow for irregular peaks of information to occur, as the ratio of words per minute cannot be altered. As a result, the future describers eventually learn to calculate, at least intuitively, the approximate amount of words available for a given description, thus deciding to pick more or less items off the list. As for "timing", relevance is determined in the process of deciding whether to advance or postpone the description of an action. Formally, adequacy and specificity of linguistic choices will correlate with the efficiency of the description. Better choices will convey more relevant information.

However detailed these criteria intend to be, there is also a level of vagueness in the description of some categories, especially the ones deemed most important for relevance. See, for example "Addition of non-intended pragmatic information", "suppression of visual, acoustic or textual information needed to understand the text", "describing obvious elements". Such vagueness is required for the evaluation criteria to be suitable for any hypothetic text. As it has been pointed out, these criteria apply directly in the less context-ridden decisions, but our primary intention with this paper is to systematise, as much as possible, the whole process of relevance. The next factor is therefore designed to provide a solid ground for context-determined decisions, regarding what is intended or not intended in a given scene, what is required in order to understand, what is obvious or not. 


\section{Film narrative}

This level focuses on an interdisciplinary approach which has already been advocated by other scholars. According to Salway (2007, p. 152) "language of AD is shaped in part by its narrative function"; but not only that, this narrative function of the descriptions can be exploited to enhance the visual narration of a given scene, as presented by Kruger (2009). As we have seen before, Remael and Vercauteren at Artesis Hogeschool Antwerpen are working on film narratology and AD not only as a research topic, but also applied specifically to teaching. And last but not least, the intersection between film narrative and $\mathrm{AD}$ is also confirmed by everyday practice. A purely filmic tool such as the introduction of a new scene is also one of the most relevant bits of information for a description, and is usually conveyed by means of words depicting the 'story time', like night, morning, dusk or later (cf. Salway 2007, p. $165)$.

The deconstruction of film narrative inevitably depends on some degree of personal interpretation which goes unnoticed to the lay viewer (Bordwell, 1985, p. 48):

For the viewer, constructing the story takes precedence; the effects of the text are registered, but its causes go unremarked. [...] The spectator simply has no concepts or terms for the textual elements and systems that shape responses. It is the job of theory to construct them, the job of analysis to show them at work.

Describers and, in our case, students, must act as conscious viewers and analyse such textual elements and systems. By confronting their decisions to a narrative analysis, they can discern pragmatic intentions, what is needed to understand the scene, what is obvious or not and, very importantly, justify their decisions. From a teaching point of view, it is essential that the theoretical framework applied to the narrative analysis be clearly specified, as it was important for the evaluation criteria. Thus, students can pick relevant items on known and shared grounds. Remael and Vercauteren's frame could apply perfectly at this point, but it was far too detailed for our purposes: in a one-term 
course which also included SDH and game localisation there was little time to properly work with the students on the twelve narrative strategies proposed by Lucey (1996). Instead, we focused our narrative analysis on an equally thorough but less detailed model following David Bordwell's theory of the principles of narration. His proposal is to analyse a film as consisting of two systems and a remaining body of material, as illustrated in this diagram $(1985$, p. 50$)$ :

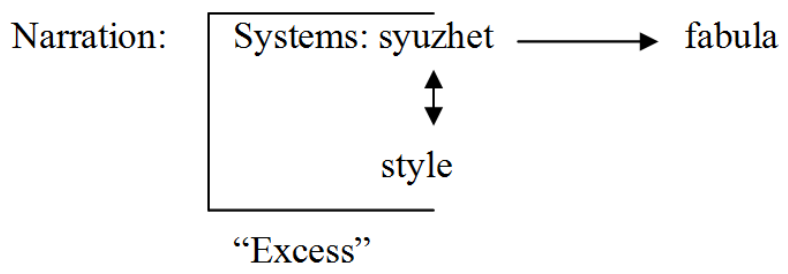

Fig. 2: Film as phenomenal process (Bordwell, 1985)

The fabula, or story, refers here to the chronological, cause-and-effect chain of events which will later be materialised by means of the two systems, syuzhet and style. It consists of the unorganised essential information which occurs within a given duration and within a spatial field, but it is never materially present on the screen or soundtrack. The spectator will only reach the fabula by a series of inferences, driven by the syuzhet and style.

The syuzhet, or plot, is the actual arrangement and presentation of the fabula, it can be compared to the architecture of the film. Bordwell considers it to be a system, because it arranges story situations and events according to specific principles, namely narrative logic, time and space. Narrative logic stands for the various relationships between phenomena, which are, according to Bordwell, mainly causal. The syuzhet can order these phenomena in a linear way or deliberately complicate causal relationships by means of gaps, dilations, or redundancies, or even trigger associations by means of 
parallelisms. As for the use of time, the plot can guide the viewer through the story by presenting events in different orders, durations and frequencies, thus assisting or blocking the construction of the fabula time. Similarly, the space in which the story takes place can be either very smoothly presented by the plot or impeded by means of suspensions, cuts and deliberate confusions. In Bordwell's words (1985, p. 52):

[...] the syuzhet aims not to let us construct the fabula in some logically pristine state but rather to guide us to construct the fabula in a specific way, by arousing in us particular expectations at this or that point, eliciting our curiosity or suspense, and pulling surprises along the way.

The plot is independent of the medium, the same patterns can be transformed into a novel, a play or a film. Style, on the contrary, is ingredient to the medium, in that it refers to the use of cinematic devices to represent the plot. The usual tendency is for the film techniques which constitute the style to assist the plot's process of cueing the spectator to construct the story, but their relationship can also be one of disparity, to the point that style patterns can be as important as syuzhet patterns, a phenomenon mainly caused by an artistic motivation (ibid: 275).

Finally, there are of course elements in a fiction film which go beyond narration. These are what Bordwell calls, after Kristin Thompson, excess: "materials which may stand out perceptually but which do not fit either narrative or stylistic patterns" (Bordwell, 1985, p. 53.), such as colours, some sounds or expressions.

Thus, in Bordwell's definition, narration in the fiction film is "the process whereby the film's syuzhet and style interact in the course of cueing and channelling the spectator's construction of the fabula" (ibid.). Audio description goes hand in hand with plot and style, in that it assists the construction of the fabula by the receiver, and therefore it is in the analysis of the plot and style where the focus of our work with the students lies. The specific narrative systems and elements will be determined by the context of each film -and each scene-, and should be linguistically mirrored by the description: when 
facing a scene with a linear presentation of events, the describer must be very aware not to advance action; when a film deliberately plays with the presentation of time, it should be regarded as a clue for the describer to carefully parallel this alteration in the linguistic form; if the movements of the camera highlight the tension of a specific scene, this tension should also be present in one way or another in the description; and even the "excess" elements are to be considered relevant if the narrative analysis confirms that they assist the plot.

Our hypothesis, following Remael and Vercauteren (2007), is that after having analysed the film within this framework, students are better prepared to embark on the process of pointing out the most relevant elements for their verbal rendering of the story. In other words, the narrative clues function as relevance clues for the description.

\section{Conclusions}

Subjectivity lies at the heart of any audio description. Every sound, every camera move, every glance in a film forces the describer to decide whether it is important enough to be included in the final text. No systematic research to date has focused on the grounds on which such decisions are taken, and therefore the process of prioritisation in professional descriptions remains hidden. This intrinsic characteristic of audio descriptions poses a serious problem in a didactic context, where objectivity and systematisation are essential ingredients, both for assessment and for the teachinglearning processes themselves.

The theoretical framework presented in this paper is an attempt to reconcile the subjectivity of $\mathrm{AD}$ with the systematic approach that teaching demands. Starting from an inclusive list of items to be described, which comprises the clues that should ideally be transferred to the description, we detailed a set of $\mathrm{AD}$-specific evaluation criteria and a frame to analyse the text according to Bordwell's basic concepts of film narrative. 
By applying this framework our aim is to cover three main objectives: first, helping the students decide which elements must be prioritised in any given situation; second, systematising the decision-making process and, last, raising their awareness during the process in order to ensure that their decisions are based on solid grounds. This theoretical approach has so far only been tested on one group of 59 students yielding positive results for all three objectives; further tests, however, must be carried out in order to assess to what extent the combination of the three factors improves the teaching-learning process and helps produce more consistent audio descriptions. 


\section{References}

Asociación Española de Normalización y Certificación [AENOR] (2005).

Audiodescripción para personas con discapacidad visual. Requisitos para la audiodescripción y la elaboración de audioguías. UNE 153020 [Audio description for the visually impaired. Requisites for audio description and audio guides]. Madrid: AENOR.

Audetel (2000). ITC Guidance on Standards for Audio Description. Retrieved August 15, 2009 from http://www.ofcom.org.uk/static/archive/itc/itc_publications/codes_guidance/audio _description/index.asp.html

Badia, T., Matamala, A. (2007). La docencia en accesibilidad en los medios [Teaching media accessibility]. Trans. Revista de Traductología, 11, 61-71

Bordwell, D. (1985). Narration in the Fiction Film. London: Routledge.

Bourne, J., Jiménez, C. (2007). From the visual to the verbal in two languages: a contrastive analysis of the audio description of The Hours in English and Spanish. In J. Díaz Cintas, P. Orero \& A. Remael (Eds.), Media for All: Subtitling for the Deaf, Audio Description and Sign Language (pp. 175-188). Amsterdam: Rodopi. Braun, S. (2008). Audio Description research: state of the art and beyond. Translation Studies in the New Millennium, 6, 14-30.

Innovació docent en educació superior [IDES] (2008). Carpetes d'aprenentatge a l'educació superior: una oportunitat per repensar la docència [Learning portfolios in higher education: an opportunity to rethink teaching] (Col. Eines, 5). Bellaterra: Universitat Autònoma de Barcelona. 
Hurtado, A. (Dir.) (1999). Enseñar a traducir. Metodología en la formación de traductores e intérpretes [Teaching to translate. Methodology in translation and interpreting training]. Madrid: Edelsa.

Klenowski, V. (2004). Desarrollo de portafolios para el aprendizaje y la evaluación [Portfolio development for learning and evaluation]. Madrid: Narcea.

Kruger, J.-L. (2009, June). Narratology and AD: Focalisation in written and filmic narrative. Paper presented at the Advanced Research Seminar on Audio Description, Barcelona, Spain.

Lucey, P. (1996). Twelve strategies for enhancing visual content. Creative Screenwriting. Writing Independent Film, 3(1), 98-106.

Matamala, A., Orero, P. (2007). Designing a course on audio description and defining the main competences of the future professional. Linguistica Antverpiensia, 6, $329-344$.

Orero, P. (2007). Sampling audio description in Europe. In J. Díaz Cintas, P. Orero \& A. Remael (Eds.), Media for All: Subtitling for the Deaf, Audio Description and Sign Language (pp. 111-125). Amsterdam: Rodopi.

Poethe, H. (2005) Audiodeskription - Entstehung und Wesen einer Textsorte. In U. Fix (Ed.), Hörfilm. Bildkompensation durch Sprache. Linguistisch-filmischsemiotische Untersuchungen zur Leistung der Audiodeskription in Hörfilmen am Beispiel desFilms Laura, mein Engel aus der Tatort-Reihe (pp. 33-48). Berlin: Erich Schmidt Verlag.

Remael, A., Vercauteren G. (2007). Audio describing the exposition phase of films: teaching students what to choose. Trans. Revista de Traductología, 11, 73-93. 
Salway, A. (2007). A corpus-based analysis of audio description. In J. Díaz Cintas, P. Orero \& A. Remael (Eds.), Media for All: Subtitling for the Deaf, Audio Description and Sign Language (pp. 151-174). Amsterdam: Rodopi.

Turner, J. (1998). Some characteristics of audio description and the corresponding moving image. In C. Preston (Ed.), Proceedings of $61^{\text {st }}$ ASIS Annual Meeting, vol. 35 (pp. 108-117). Medford, New Jersey: Information Today.

Vercauteren, G. (2007). Towards a European guideline for audio description. In J. Díaz Cintas, P. Orero \& A. Remael (Eds.), Media for All: Subtitling for the Deaf, Audio Description and Sign Language (pp. 139-150). Amsterdam: Rodopi.

Yeung, J. (2007). Audio description in the Chinese world. In J. Díaz Cintas, P. Orero \& A. Remael (Eds.), Media for All: Subtitling for the Deaf, Audio Description and Sign Language (pp. 231-244). Amsterdam: Rodopi. 